\title{
Immunocytochemistry of Sequence-related Neuropeptides in Drosophila
}

\author{
M. F. TIBBETTS* and R. NICHOLS*† \\ *Departments of Biology and TBiological Chemistry, 830 N. University Street, University of \\ Michigan, Ann Arbor, MI, 48109-1048, USA (Reprint requests to RN)
}

\begin{abstract}
Based on structure, activity, and expression, the Drosophila drosulfakinin I peptide (DSK I; FDDY $\left(\mathrm{OSO}_{3} \mathrm{H}\right)$ GHMRFamide) is similar to the vertebrate peptide, cholecystokinin. ${ }^{1}$ Dromyosuppressin (DMS; TDVDHVFLRFamide) is an abundant peptide isolated from adult Drosophila ${ }^{2}$ which shares a high degree of sequence homology with peptides isolated from chicken, cockroach, fleshfly, and locust. DSK I and DMS, encoded by different precursors, have similar expression patterns in larval brain tissue; each localizes to cells in the anterior and medial protocerebrum. Because of the precedence for coexistence of neural messengers, ${ }^{3}$ it was of interest to determine the cellular expression patterns relative to one another. The question of whether the two peptides were expressed in the same cells was resolved using an immunofluorescent double-labeling technique developed for sequence-specific antisera raised in separate animals of the same species. Double labeling was done using a combination of indirect and direct immunofluorescence. DSK I and DMS were shown to localize to different cells in close proximity to one another in the larval brain. The non-overlapping expression patterns of these peptides illustrate the complete lack of cross-staining with this technique.
\end{abstract}

\section{Introduction}

Since the isolation of FMRFamide from mollusc as a cardioexcitatory peptide ${ }^{4}$ numerous peptides structurally-related to FMRFamide have been identified from both vertebrate and invertebrate neural tissues. FMRFamide-related peptides are abundant neuropeptides widely distributed throughout the animal kingdom which share the common C-terminal sequence -RFamide. Tissue distribution and activity studies suggest that these peptides act as transmitters, regulators, and modulators in the central

Date received 18 January 1993

Date accepted 18 February 1993 nervous system and function in a broad range of important physiological processes.

Drosophila melanogaster contain multiple -RFamide-containing peptides encoded by different genes. $^{2}$ One gene encodes drosulfakinin I (DSK I, FDDY $\left(\mathrm{OSO}_{3} \mathrm{H}\right)$ GHMRFamide), and another gene encodes dromyosuppressin (DMS, TDVDHVFLRFamide). DSK $I$ is a cholecystokinin homologue and DMS shares a high degree of structure identity with cockroach and fleshfly peptides both of which have been demonstrated to inhibit gut motility. 5,6

Antisera to FMRFamide stains a certain set of neurons in Drosophila melanogaster and provides 
important information to identify the expression of FMRFamide-related peptides. ${ }^{7}$ However, the presence of multiple -RFamide-containing peptides in Drosophila and the specificity of the FMRFamide antisera to the C-terminal -RFamide means that the immunohistochemical data cannot be interpreted unambiguously. To begin to study the expression of these sequence-related peptides in Drosophila neural tissue, sequence-specific antisera were generated and characterized.

From separate experiments, immunocytochemical data indicated that DSK I and DMS were each expressed in two sets of cells bilaterally symmetrical to the midline in Drosophila larval brain. Due to the cell sizes, shapes, and positions it was unclear from the data obtained whether the cellular expression patterns were distinct or overlapping and, if so, to what extent.

Simultaneous immunofluorescent detection of two sequence-related antigens is a valuable tool for resolving similar or overlapping expression patterns. A double-labeling experiment in which two fluorochromes are used to detect different antigens requires that each antigen be separately recognized. This is often accomplished by raising antisera in different host species and using host-specific second antibodies for detection. Another strategy used in double-labeling studies is to conjugate a substance directly to a primary antisera. However, this procedure may be difficult if the amount of primary antisera is limiting.

This manuscript describes a convenient technique for double labeling with two polyclonal antisera both raised in rabbits in which only one sequence-specific class of antisera has been directly labeled with a fluorochrome. The technique has been applied to resolve the similar expression patterns observed for two Drosophila neuropeptides that are structurally related.

\section{Materials and methods}

\section{Antibody production}

The peptides FDDYGHMRFamide, FMRFamide, TDVDHVC, TDVDHV-MAP, ${ }^{8}$ and TDVDHVFLRFamide were synthesized using an Applied Biosystems model 430A solid phase peptide synthesizer and purified by preparative reversed-phase HPLC. The structures of the synthetic peptides were confirmed by mass spectrometry, amino acid analy- sis, and automated Edman degradation. Masses were determined by fast atom bombardment mass spectrometry (FAB MS) using a Kratos MS-50 mass spectrometer. The matrix was thioglycerol and ions were detected in the positive mode with peak matching done against cesium iodide ion clusters. Amino acid analyses were done after acid hydrolysis in $6 \mathrm{~N}$ $\mathrm{HCl}$ for $24 \mathrm{~h}$ at $110^{\circ} \mathrm{C}$ in vacuo. The hydrolysates were dried under a nitrogen stream and analyzed using a Beckman 6300 amino acid analyzer. The synthetic peptides were sequenced using an Applied Biosystems model 470 automated protein sequencer with online detection of PTH-amino acids.

Antisera were raised in New Zealand white rabbits to TDVDHVC conjugated to thyroglobulin through the cysteinyl residue using a heterobifunctional crosslinker. ${ }^{9}$ The initial immunizations were by intradermal injections at multiple sites using a total of $1 \mathrm{mg}$ of antigen emulsified in Freund's complete adjuvant. Subsequent boosts were given every 2 weeks by subcutaneous injections of a total of 0.5 mg of antigen emulsified in Freund's incomplete adjuvant. Titers were analyzed by indirect immunofluorescence of whole mount third instar larval central nervous systems as described. ${ }^{7}$ Antisera to FDDYGHMRFamide were generated as previously described. ${ }^{1}$

\section{Affinity purification of sequence-specific antisera}

A peptide affinity column was made by coupling TDVDHV-MAP to Affi-gel 10 (Bio-Rad Labs) in dry DMSO and 1\% triethylamine. The amount of peptide coupled to the affinity resin was $2 \mathrm{mg}$ peptide $/ \mathrm{ml}$. The column was washed with 10 column volumes of $5 \mathrm{x}$ PBS prior to antisera application, crude antisera diluted $1: 1$ with $10 \times$ PBS were applied to the column at a flow rate of $10 \mathrm{ml} / \mathrm{h}$, and the column was then washed with 10 column volumes of $5 x$ PBS. TDVDHV-specific antisera were eluted from the column with 5 column volumes of $0.1 \mathrm{M}$ sodium citrate $\mathrm{pH} 2.5$, neutralized by collecting

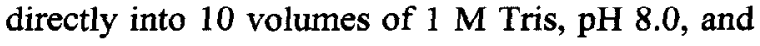
subsequently dialyzed against 4 liters of $0.01 \times$ PBS at $4^{\circ} \mathrm{C}$ for $24 \mathrm{~h}$. The affinity-purified antisera were then freeze-dried and stored at $-20^{\circ} \mathrm{C}$. DSK-specific antisera were purified as previously described. ${ }^{1}$

Detection of immunoreactive material

FITC (Molecular Probes) was directly conjugated to 
affinity-purified antisera using the method described by Harlow and Lane. ${ }^{10}$ FITC-labeled goat anti-rabbit antisera (Sigma) were used to detect both primary antisera in the same preparation. In double-labeling studies, FITC-labeled TDVDHV-specific antisera and TRITC-labeled goat anti-rabbit antisera (Sigma) were used to detect DMS and DSK I immunoreactive materials, respectively. Whole mount third instar larval Drosophila central nervous systems were prepared as described by White et al. ${ }^{7}$

In double-labeling experiments, neural tissue was incubated in succession with 1) DSK-specific antisera for $4 \mathrm{~h}$ or longer, 2) TRITC-labeled goat antirabbit antisera for 2-3 h, 3) pre-immune rabbit antisera for $1 \mathrm{~h}$, and 4) FITC-labeled TDVDHV-specific antisera and pre-immune rabbit antisera for $4 \mathrm{~h}$ or longer. Tissue was washed between incubations and mounted for observation.

Control studies were done to ensure that the fluorescence observed in the double-labeling experiments could be assigned to DMS and DSK I peptides. Experiments included incubating larval central nervous systems with no antisera, no second antisera, or both primary antisera inactivated by preabsorption with FMRFamide, TDVDHVFLRFamide, and/or FDDYGHMRFamide at $0.0001 \mathrm{M}$ and $0.01 \mathrm{M}$.

\section{Results and discussion}

The insect brain contains neurosecretory cells which are characterized by the presence of membranebound secretory granules and thought to make use of biologically active peptides as messenger substances." To learn about the role(s) of peptidergic neurons in Drosophila brain, we have undertaken the task to isolate and identify the naturally-occurring peptides containing -RFamide and to determine cellular expression using sequence-specific antisera. The expression patterns of specific neuropeptides used in conjunction with genetic and molecular studies may provide the opportunity to determine peptide function(s).

Antisera raised to FMRFamide recognize numerous cells in the larval central nervous system including cells in the medial and anterior protocerebrum of the larval brain. ${ }^{7}$ Several cells in the medial protocerebrum contain FMRFamide-like immunoreactive material; the cells designated MP1 are near the

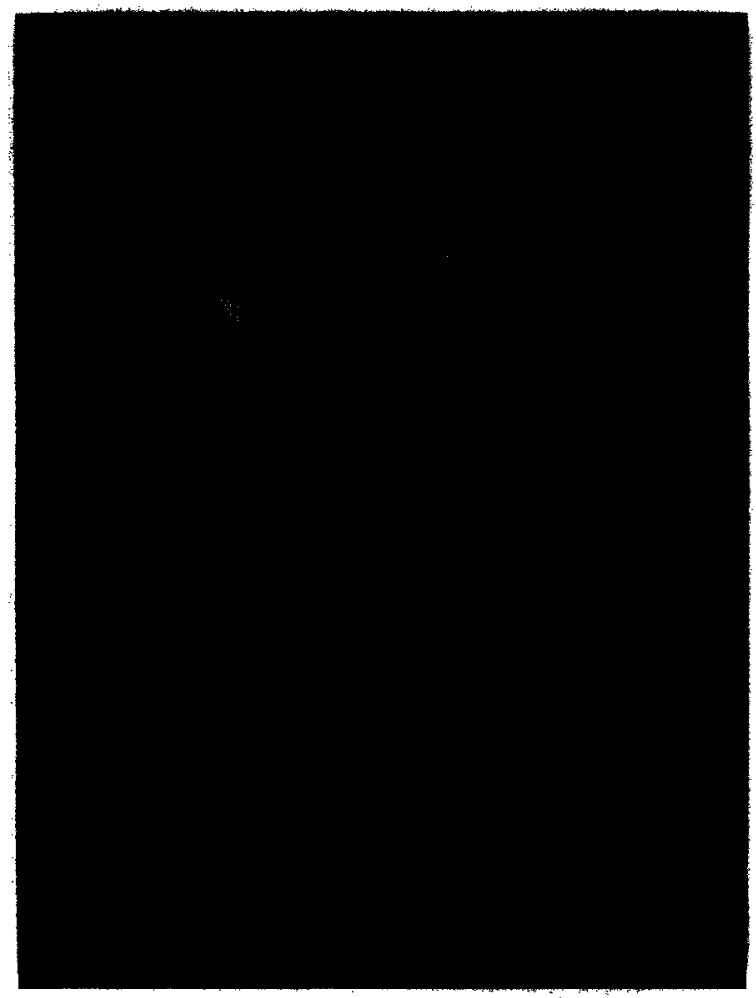

Fig. 1 DMS immunoreactivity in third instar larval central nervous system. DMS immunoreactive material is present in two cells in the medial protocerebrum (open arrow) and two cells in the anterior protocerebrum (closed arrow).

midline, and the MP2 cells are more lateral. In the anterior protocerebrum, the cells SP1 are near the midline, while the SP3 cells are more lateral.

However, since antisera to FMRFamide recognize the C-terminal -RFamide which is common to many Drosophila peptides, the results cannot be interpreted unambiguously. Therefore, it is of importance to have sequence-specific antisera available to these peptides to resolve the expression pattern of individual peptides and to address whether these peptides coexist with one another or other neural messengers.

Indirect immunofluorescent data indicate DMSspecific immunoreactivity is expressed in cells of the medial and anterior protocerebrum of the larval brain (Fig. 1) in a similar pattern as DSK I. ${ }^{1}$ Because of the similar expression patterns and the precedence for coexistence in the nervous system, ${ }^{3}$ it was of interest to establish the cellular expression of these neuropeptides relative to one another. Reasons that cells could not be assigned from separate experiments using only one primary antisera include: 


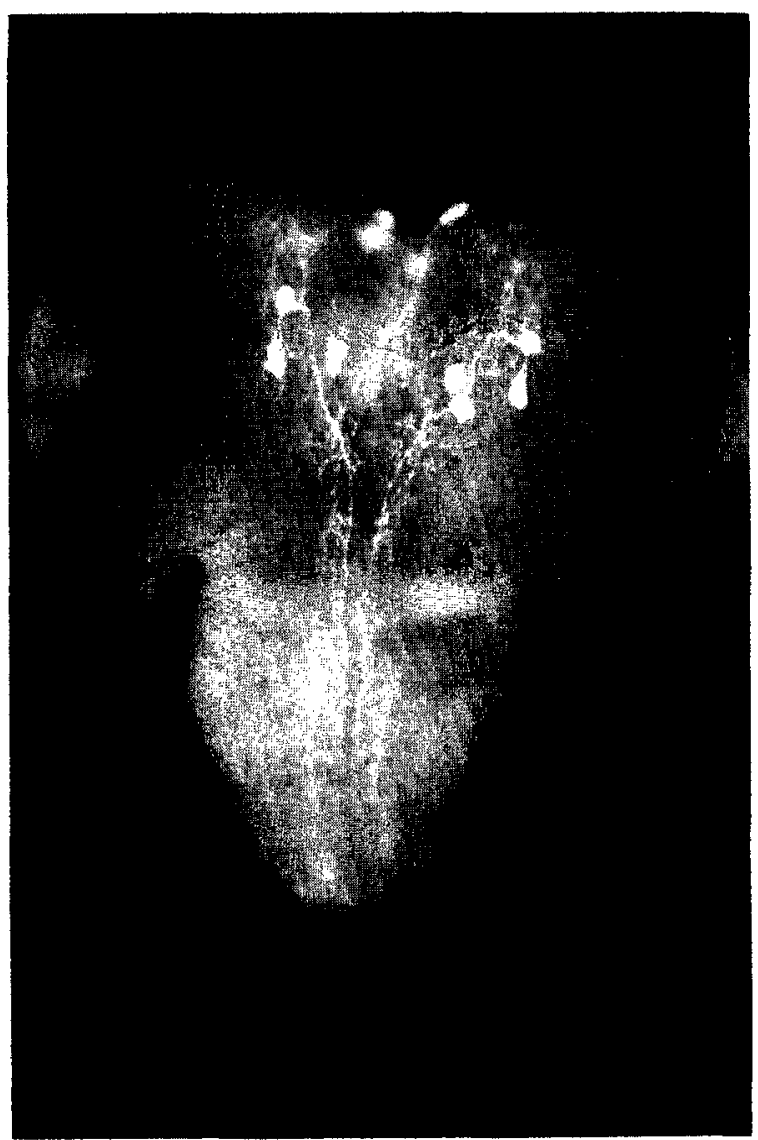

Fig. 2 DMS and DSK I immunoreactivity in the third instar larval central nervous system. Both sequence-specific primary antisera were detected with FITC-labeled goat anti-rabbit antisera in the same tissue. The result was an increase in the number of cells containing immunoreactive material.

1. The FMRFamide-like immunoreactive cells in both the medial and anterior protocerebrum are in close proximity and are similar in shape and size, and

2. The exact position of a cell in a whole mount tissue preparation is difficult to determine.

When both sequence-specific antisera were used in a single preparation an increase in the number of immunoreactive cells was observed over using either antisera alone indicating that the expression patterns were not identical (Fig. 2). However, based on experiments using both primary antisera and one labeled second antisera, it was not possible to assign expression of a particular peptide to any certain cell(s).

A double-labeling protocol using both indirect and direct immunofluorescence was developed.
TRITC-labeled goat anti-rabbit antisera were used to detect the first primary antisera after which the open sites on the anti-rabbit secondary antisera were blocked with non-immune rabbit sera and the second primary antisera were detected by direct conjugation to a fluorochrome (FITC). The staining of the larval central nervous system tissue reveals distinct expression patterns for DSK I and DMS peptides (Fig. 3). DSK I immunoreactive material is expressed in the MP1 cells of the medial protocerebrum and the SP1 cells of the anterior protocerebrum. DMS immunoreactive material is expressed in the MP2 cells of the medial protocerebrum and the SP3 cells of the anterior protocerebrum.

Control experiments support this conclusion:

1. Preincubation of both primary antisera with TDVDHVFLRFamide completely abolished only the signal due to FITC

2. Preincubation of both primary antisera with FDDYGHMRFamide abolished only the signal due to TRITC

3. Preincubation of antisera with both peptides abolished all fluorescence, and

4. Preincubation of either antisera with FMRFamide did not affect any signal (data not shown).

The design of the double-labeling experiment was technically limited because attempts at raising antisera in different species was unsuccessful and the amount of DSK-specific antisera available was not sufficient for direct conjugation of a fluorochrome. The open sites on the anti-rabbit antisera were blocked with non-specific pre-immune rabbit antisera before incubation with the FITC-labeled TDVDHV-specific antisera because both antisera were raised in rabbits; numerous sources of pre-immune rabbit antisera were used successfully and no prior purification was required. To fail to block these sites led to all cells fluorescing green (data not shown).

No difference in signal intensity or expression pattern was observed when the order of application was varied in studies done to detect both primary antisera with the same fluorochrome-labeled second antisera. However, the order of application was important for the double-labeling studies. Changing the order of application of the primary antisera, e.g., applying the FITC-labeled TDVDHV-specific antisera first and then the DSK-specific antisera followed by TRITC-labeled goat anti-rabbit antisera, resulted in both sets of cells fluorescing red (data not shown). 

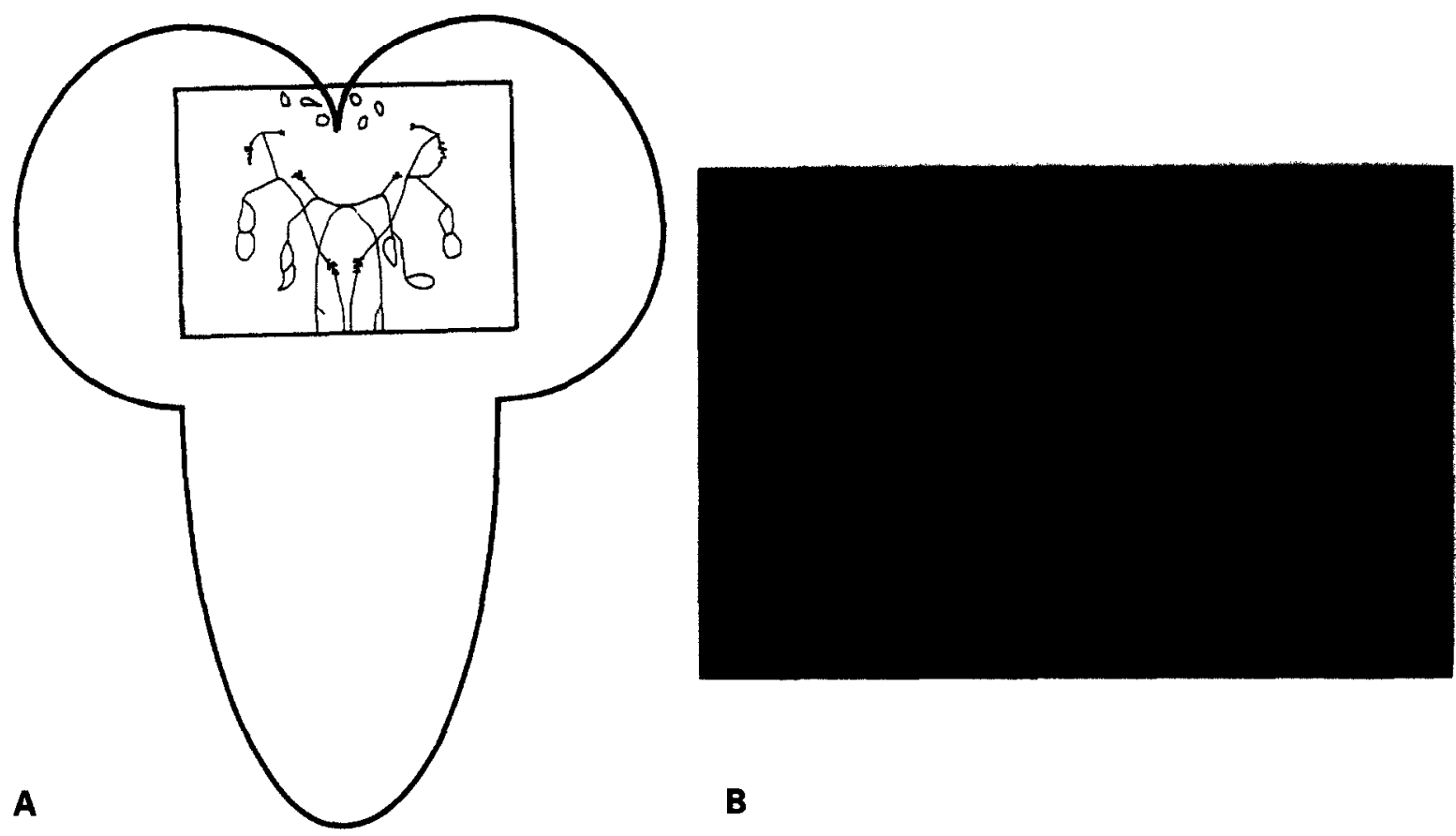

Fig. 3 (A) A schematic drawing of the larval central nervous system. A rectangle is used to illustrate the area from which doublelabeling immunoffuorescence data are presented. (B) Double-labeling immunofluorescence of Drosophila third instar larval central nervous system. FTTC-labeled TDVDHV-specific antisera (green fluorescent signals) represent DMS immunoreactive materials and TRITC-labeled goat anti-rabbit antisera (red fluorescent signals) represent DSK immunoreactive materials. DMS is expressed in MP2 and SP3 cells, and DSK I is expressed in MP1 and SP1 cells.

The use of sequence-specific antisera and doublelabeling immunofluorescence will be important in identifying the cellular expression patterns of these neuropeptides in mutants.

\section{Acknowledgements}

This work was supported in part by grants to RN. from the National Science Foundation (BNS90906237), and the National Institute of Mental Health (R03MH4655901). Peptide syntheses, analyses, and conjugations were done by personnel at The University of Michigan Protein Structure Facility under the direction of P. C. Andrews, Ph.D. The authors thank P. C. Andrews for helpful discussions on antisera purification. J. E. Hoover is thanked for continued support and early morning discussions which were both insightful and thought provoking.

\section{References}

1. Nichols, R. (1992a). Isolation and characterization of the Drosophila drosulfakinin neural peptide gene product, DSKI. Mol. Cell. Neurosci. 3: 342-347.

2. Nichols, R. (1992b). Isolation and structural characterization of Drosophila TDVDHVFLRFamide and FMRFamide-containing neural peptides. J. Mol. Neurosci. 3: 213-218.

3. Hökfelt, T., Johansson, O., Ljungdahl, \&., Lundberg, J. M. and Schultzberg, M. (1980). Peptidergic neurones. Nature 284: 515-521.

4. Price, D. A. and Greenberg, M. J. (1977). Structure of a molluscan cardioexcitatory neuropeptide. Science 197:670-672.
5. Holman, G. M., Cook, B. J. and Nachman, R. J. (1986). Isolation, primary structure and synthesis of leucomyosuppressin, an insect neuropeptide that inhibits spontaneous contractions of the cockroach hindgut. Comp. Biochem. Physiol. 85C: 329-333.

6. Fonagy, A., Schoofs, L., Proost, P., Vandamme, J., Bueds, H. and Deloof, A. (1992). Isolation, primary structure, and synthesis of neomyosuppressin, a myoinhibiting neuropeptide from the grey fleshfly, Neobellierria-Bullata. Comp. Biochem. Physiol. 102C: 239-245.

7. White, K., Hurteau, T. and Punsal, P. (1986). NeuropeptideFMRFamide-like immunoreactivity in Drosophilia: Development and distribution. J. Comp. Neurol. 247:430-438.

8. Posnett, D. N. and Tam, J. P. (1989). Multiple antigenic peptide method for producing antipeptide site-specific antibodies. In Langnone, J. J. (eds) Methods in Enzymology. Academic Press, N.Y. 178: 739-746.

9. Yoshitake, S., Yamada, Y., Ishikawa, E. and Masseyeff, R. (1979). Conjugation of glucose oxidase from Aspergillus niger and rabbit antibodies using $\mathbf{N}$-hydroxysuccinimide ester of N-(4-carboxycyclohexylmethyl)-maleimide. Eur. J. Biochem. 101: 395-399.

10. Harlow, E. and Lane, D. (1988). Isothiocyanate labeling. In Antibodies: A laboratory manual. Cold Spring Harbor Press, N.Y. p. 354-355.

11. Scharrer, B. (1958). Neuro-endocrine mechanisms in insects. In: Barmann, W., Hanstrom, B., Scharrer, E. and Sharrer, B. (eds) Proceedings of the Second International Symposium on Neurosecretion. Berlin-Göttingen-Heidelberg: SpringerVerlag. p. 79-84. 